\title{
Corrosion Caused by Sulfur Dioxide in Reinforced Concrete
}

\author{
Fernando B. Mainier, Paulo César Fernandes de Almeida, Bruna Nani, \\ Lisiane H. Fernandes, Marcone Freitas dos Reis \\ Escola de Engenharia, Universidade Federal Fluminense, Niterói, Brazil \\ Email:fmainier@uol.com.br
}

Received 3 November 2015; accepted 1 December 2015; published 4 December 2015

Copyright (C) 2015 by authors and Scientific Research Publishing Inc.

This work is licensed under the Creative Commons Attribution International License (CC BY). http://creativecommons.org/licenses/by/4.0/

c) (i) Open Access

\begin{abstract}
The burning of fuel oil with high sulfur content in diverse industrial segments results in the generation of oxidized sulfur compounds $\left(\mathrm{SO}_{\mathrm{x}}\right)$. These emissions, directly or indirectly, lead to the deterioration of air quality with consequences including the development of lung diseases in the surrounding population, the generation of acid rain and damage to civil constructions, such as public buildings, public squares, historic monuments, bridges, etc. This article describes the mechanisms of corrosion that occur in reinforced concrete deterioration observed in an industrial plant by the action of direct emissions of sulfur dioxide. $\mathrm{SO}_{2}$ in this case study is from the burning of fuel oil high sulfur content from chimney of an industrial boiler. The deterioration of concrete was evaluated in the laboratory showing the formation of calcium sulfate and calcium sulfate hydrate associated with aluminum oxide $\left(\mathrm{Al}_{2} \mathrm{O}_{3}\right)$ and calcium oxide (CaO).
\end{abstract}

\section{Keywords}

Corrosion, Sulfur Compounds, Contamination, Mechanisms of Corrosion, Reinforced Concrete

\section{Introduction}

Corrosion is a phenomenon that can occur spontaneously or not, usually defined as the deterioration of a material or its properties as a function of chemical, electrolytic or electrochemical process intrinsically associated with a corrosive medium.

Emissions of oxidized sulfur compounds, represented by $\mathrm{SO}_{\mathrm{x}}$, from burning fossil fuels, the petroleum and petrochemical industries, metallurgical production of carbon steel, copper, zinc and lead, cement plants and other chemical industries, have had consequences in the form of environmental contamination and corrosion since the 1950s. A report from Göteborg University [1] revealed that sulfur compounds are expelled into the atmos- 
phere at a rate of about 345,000 tons per year of $\mathrm{SO}_{2} ; 90 \%$ of this value is credited to the burning of fossil fuels for the generation of electricity and heat.

Based on the research of Moskalyk \& Alfantazib [2], there are about 112 operating smelting furnaces for the production of copper throughout the world, with an annual production of more than 14 million tons of blister copper. More than $60 \%$ of this production is generated in countries where environmental laws are weak, leading to high emissions of $\mathrm{SO}_{2}$ and $\mathrm{CO}_{2}$.

In Serbia, according to Tasić et al. [3], copper production through pyrometallurgical copper by the direct burning of chalcocite $\left(\mathrm{Cu}_{2} \mathrm{~S}\right)$ and chalcopyrite $\left(\mathrm{CuFeS}_{2}\right)$ ore has been ongoing for more than 100 years and currently produces approximately 34,000 t/y of copper and 70,000 t/y of sulfuric acid $\left(\mathrm{H}_{2} \mathrm{SO}_{4}\right)$.

Environmental research carried out by Dimitrijević et al. [4] has shown that the high $\mathrm{SO}_{2}$ levels found in the town of Bor, Serbia, are due to burning of fossil fuels used in maintaining the high temperatures of the pyrometallurgical process, the generation of electricity and heat, and also from the exhaust/leak of $\mathrm{SO}_{2}$ of converters, because sulfide ore copper production requires the recovery of $\mathrm{SO}_{2}$ in the form of sulfuric acid. The average acceptable annual values in the region are $50 \mu \mathrm{g} / \mathrm{m}^{3}$; however, values of $283 \mu \mathrm{g} / \mathrm{m}^{3}$ have been recorded. The study concluded that the region's air quality was bad and probably reduced the quality of life of the inhabitants.

There is no doubt that both the emission of $\mathrm{SO}_{2}$ and acid rain create environmental problems and negatively impact public health. Based on these facts, Table 1 presents human health indices for the $\mathrm{SO}_{2}$ levels required to function outdoors, according to the EPA (Environmental Protection Agency) [5] [6].

Deterioration in the quality of the atmosphere in cities close to large industrial complexes has been observed in vegetation, as the most sensitive leaves become yellow or dead. However, this damage can also be detected on civil constructions such as viaducts and bridges, industrial plants, in electrical wiring, etc.

This work aimed to describe the mechanism of corrosion observed in the deterioration of reinforced concrete in industrial plants burning fuel oil with high sulfur content with consequently high $\mathrm{SO}_{2}$ emissions.

\section{Formation of Sulfuric Acid in the Atmosphere Resulting from the Burning of Residual Fuel Oil with a High Sulfur Content}

Residual fuel oil is generally an important commercial liquid fuel used for power purposes. It consists of a mixture of the liquid fractions obtained from the distillation of crude oil and liquid residues of the cracking process. The constituents of residual fuels are more complex than those of gas oils. A major part of the polynuclear aromatic compounds, asphaltenes, and heavy metals found in crude oils is concentrated in the residue. Fuel oil is classified of according to its physico-chemical properties, such as viscosity, flashpoint, distillation temperature, pour point, carbon residue, ash, and total sulfur. All these parameters, established with the respective testing methodologies, are based on the ASTM (American Society for Testing and Materials) international standards. Fuel oils are very viscous, though low viscosity is a desirable feature because it facilitates handling, transport on cold days and atomization during burning.

Sulfur in residual fuel oil is mainly present in the form of organosulfur compounds. Organosulfur compounds may generally be classified as acidic ornon-acidic. Acidic sulfur compounds are the mercaptans, thiophene, sul-

Table 1. Indices of $\mathrm{SO}_{2}$ for quality of life.

\begin{tabular}{|c|c|c|}
\hline $\begin{array}{l}\text { Concentration of } \\
\qquad \mathrm{SO}_{2}, \mu \mathrm{g} / \mathrm{m}^{3}\end{array}$ & $\begin{array}{l}\text { Levels in terms } \\
\text { of human health }\end{array}$ & Precautions \\
\hline $0-50$ & Good & - \\
\hline $51-100$ & Reasonable & - \\
\hline $101-150$ & Unhealthy for sensitive groups & Asthmatic people should limit physical exertion outdoors in these areas. \\
\hline $151-200$ & Insalubrious & $\begin{array}{l}\text { Children, asthmatics and people with heart or lung } \\
\text { diseases should limit physical exertion in outdoor areas. }\end{array}$ \\
\hline $201-300$ & Insalubrious & $\begin{array}{l}\text { Physical exertion should be avoided in these outdoor areas for children, } \\
\text { asthmatics, and people with heart or lung diseases. It is recommended } \\
\text { that you also avoid physical efforts in these areas. }\end{array}$ \\
\hline $301-500$ & Very toxic & $\begin{array}{l}\text { Children, asthmatics and people with heart or lung diseases } \\
\text { should stay indoors; other individuals should avoid outdoor efforts. }\end{array}$ \\
\hline
\end{tabular}


fides; disulfides are examples of non-acidic sulfur compounds found in residual fuel oil. Hydrogen sulfide $\left(\mathrm{H}_{2} \mathrm{~S}\right)$ and elemental sulfur (S) can also be found in the composition of the fuel oil. The total sulfur (representing all forms of sulfur compounds) can vary from $0.1 \%$ to $10 \%$ depending on the type of petroleum and the desulfurization processes used.

Generally, the direct burning of fuel oil with a high sulfur content primarily results in the formation of $\mathrm{CO}_{2}$, $\mathrm{CO}, \mathrm{H}_{2} \mathrm{O}$ (steam), $\mathrm{SO}_{2}, \mathrm{SO}_{3}, \mathrm{NO}_{\mathrm{x}}$, and particulates.

More than $95 \%$ - 98\% of the sulfur compounds present in fuel oil are oxidized into $\mathrm{SO}_{2}$, with the remainder as $\mathrm{SO}_{3}$. The mechanisms proposed in the literature show that part of the $\mathrm{SO}_{2}$ is oxidized in the presence of oxidizing substances to $\mathrm{SO}_{3}$ and subsequently forms $\mathrm{H}_{2} \mathrm{SO}_{4}$ when it comes in contact with water, as shown by Baird \& Cann [7]. According to Baird \& Cann [7], the reaction of $\mathrm{SO}_{2}$ with a hydroxyl radical $(\mathrm{OH})$ generates a new radical $\left(\mathrm{HSO}_{3}{ }^{\circ}\right)$, which then reacts with oxygen $\left(\mathrm{O}_{2}\right)$ and water droplets, as shown in the following reactions:

$$
\begin{gathered}
\mathrm{SO}_{2}+\left(\mathrm{OH}^{\cdot}\right) \rightarrow\left(\mathrm{HSO}_{3} \cdot\right) \\
\left(\mathrm{HSO}_{3} \cdot\right)+\mathrm{O}_{2} \rightarrow \mathrm{SO}_{3}+(\mathrm{HOO} \cdot) \\
\mathrm{SO}_{3}+\mathrm{H}_{2} \mathrm{O} \rightarrow \mathrm{H}_{2} \mathrm{SO}_{4}(\mathrm{~g}) \\
\mathrm{H}_{2} \mathrm{SO}_{4}(\mathrm{~g})+\text { many } \mathrm{H}_{2} \mathrm{O} \rightarrow \mathrm{H}_{2} \mathrm{SO}_{4}(\mathrm{aq})
\end{gathered}
$$

Other contaminants such as $\mathrm{NO}_{\mathrm{x}}$, ozone $\left(\mathrm{O}_{3}\right)$ and other oxidants or catalytic substances $\left(\mathrm{Fe}^{3+}, \mathrm{MnO}_{2}, \mathrm{~V}_{2} \mathrm{O}_{5}\right)$ can contribute to the formation of sulfuric acid and, consequently, acid rain.

According to Baird \& Cann [7], as $\mathrm{SO}_{2}$ is partially soluble in water, it forms sulfurous acid $\left(\mathrm{H}_{2} \mathrm{SO}_{3}\right)$ as shown in the following reaction:

$$
\mathrm{SO}_{2}(\mathrm{~g})+\mathrm{H}_{2} \mathrm{O}(\mathrm{aq}) \rightleftarrows \mathrm{H}_{2} \mathrm{SO}_{3}(\mathrm{aq})
$$

Finality, sulfurous acid isoxidized to sulfuric acid as shown in the next reaction:

$$
\mathrm{H}_{2} \mathrm{SO}_{3}+1 / 2 \mathrm{O}_{2} \rightarrow \mathrm{H}_{2} \mathrm{SO}_{4}
$$

Bravo et al. [8] observed in civil constructions that some important gaseous pollutants, like sulfur dioxide, contribute to rain acidity and lead to the formation of commonly observed gypsum $\left(\mathrm{CaSO}_{4}\right)$ in surface crusts.

Acid rain research carried out in China by Wang et al. [9] has shown that a large part is due to sulfuric acid, with $\mathrm{SO}_{4}^{2-}$ accounting for $70 \%-90 \%$ of total anions. Various sulfurous pollutants deposited over the samples can be oxidized and converted to sulfuric acid, with greater acidity and $\mathrm{SO}_{4}^{2-}$ concentrations in some parts of the sample surface. Research based on simulations of acid rain in the laboratory has confirmed the corrosive action of sulfurous compounds in concrete [10].

The corrosion of reinforcing steel structures can be highly accelerated if the concrete quality is not adequate, the concrete cover is less than that specified in the design, or through poor detailing during design and construction.

There is no doubt that both the emissions of $\mathrm{SO}_{2}$ and acid rain create environmental problems. Moreover, corrosion is accelerated in marine environments with high salinity.

\section{Mechanisms of Corrosion in Reinforced Concrete by the Action of Sulfur Dioxide and Sulfuric Acid}

Currently, cement is defined as the product of an integrated industrial activity that incorporates the extraction and processing of minerals (limestone, clays, sand), incorporated with siliceous slag from the blast furnace involved in steel manufacturing using various types of fuel, its chemical and physical transformation into clinker, and the addition of other relevant products. Finally, the final product fits the technical specifications of cement. Portland cement is a fine, grey powder that consists of a mixture of tricalcium silicate $\left(3 \mathrm{CaO} \cdot \mathrm{SiO}_{2}\right)$, dicalcium silicate $\left(2 \mathrm{CaO} \cdot \mathrm{SiO}_{2}\right)$, tricalcium aluminate $\left(3 \mathrm{CaO} \cdot \mathrm{Al}_{2} \mathrm{O}_{3}\right)$, and tetracalcium aluminoferrite $\left(4 \mathrm{CaO}, \mathrm{Al}_{2} \mathrm{O}_{3} \cdot \mathrm{Fe}_{2} \mathrm{O}_{3}\right)$, to which one or more forms of calcium sulfate $\left(\mathrm{CaSO}_{4}\right)$ have been added.

According to Roberge [11], cement paste is formed of the anhydrous cement clinker with water. The cement paste is porous in nature. An important feature of concrete is that the pores are filled with a highly alkaline solution with a pH between 12.6 and 13.8 depending on the moisture level. This highly alkaline pore solution de- 
rives from by-products of the hydration reactions in the cement clinker. Maintaining a high $\mathrm{pH}$ in the pores of the concrete is a fundamental characteristic of steel corrosion resistance.

Corrosion caused by the action of sulfur dioxide and sulfuric acid in reinforced concrete can be of three types: chemical corrosion which leads to the deterioration of concrete itself and electrochemical and electrolytic corrosion that occurs on reinforcing carbon steel. It is important to note that the occurrence of electrolytic corrosion is unlikely in reinforced concrete structures on surfaces.

\subsection{Chemical Corrosion in Concrete}

The chemical corrosion mechanism that occurs in concrete begins first with the transformation of oxidized sulfur compounds $\left(\mathrm{SO}_{2}\right.$ and $\left.\mathrm{SO}_{3}\right)$ in sulfurous acid $\left(\mathrm{H}_{2} \mathrm{SO}_{3}\right)$ and sulfuric acid $\left(\mathrm{H}_{2} \mathrm{SO}_{4}\right)$, by the following reactions:

$$
\begin{gathered}
\mathrm{SO}_{2}(\mathrm{~g})+\mathrm{H}_{2} \mathrm{O}(\mathrm{aq}) \rightleftarrows \mathrm{H}_{2} \mathrm{SO}_{3}(\mathrm{aq}) \\
\mathrm{H}_{2} \mathrm{SO}_{3}+1 / 2 \mathrm{O}_{2} \\
\rightarrow \mathrm{H}_{2} \mathrm{SO}_{4} \\
\mathrm{SO}_{3}(\mathrm{~g})+\mathrm{H}_{2} \mathrm{O}(\mathrm{aq}) \rightleftarrows \mathrm{H}_{2} \mathrm{SO}_{4}(\mathrm{aq})
\end{gathered}
$$

During the burning of the fuel oil with high sulfur content occurs the formation of $\mathrm{SO}_{2}$ and $\mathrm{CO}_{2}$. The sulfuric acid formed is more aggressive than the carbonic acid $\left(\mathrm{H}_{2} \mathrm{CO}_{3}\right)$ on the constituents of concrete. Given this fact will not be considered the carbonation of concrete and only the sulfation. Later, the formed acids migrate through the fissures and small fractures in concrete and react directly with the constituents of cement, of according to Figure 1. In this process are expected reactions of $\mathrm{SO}_{2}$, water, sulfurous acid, and sulfuric acid with calcium hydroxide free $\left(\mathrm{Ca}(\mathrm{OH})_{2}\right)$, calcium oxide $(\mathrm{CaO})$, dicalcium silicate $\left(2 \mathrm{CaO} \cdot \mathrm{SiO}_{2}\right)$ and tricalcium aluminate $\left(3 \mathrm{CaO} \cdot \mathrm{Al}_{2} \mathrm{O}_{3}\right)$, forming crystals or precipitates in the concrete matrix with volumes 5 to 30 times greater than the initial volumes of these crystals.

Therefore, the increase in the volumes of these crystals will cause a high internal pressure in the cracks consequently causing, the failure or desegregation (disagreement) of concrete, according to the following reactions:

$$
\begin{gathered}
\mathrm{CaO}+\mathrm{H}_{2} \mathrm{SO}_{3}(\mathrm{aq}) \rightarrow \mathrm{CaSO}_{3}+\mathrm{H}_{2} \mathrm{O} \\
\mathrm{CaSO}_{3}+1 / 2 \mathrm{O}_{2} \rightarrow \mathrm{CaSO}_{4} \\
\mathrm{CaO}+\mathrm{H}_{2} \mathrm{SO}_{4} \rightarrow \mathrm{CaSO}_{4}+\mathrm{H}_{2} \mathrm{O} \\
\mathrm{Ca}(\mathrm{OH})_{2}+\mathrm{H}_{2} \mathrm{SO}_{4} \rightarrow \mathrm{CaSO}_{4} \cdot 2 \mathrm{H}_{2} \mathrm{O} \\
\mathrm{CaSO}_{4} \cdot 6 \mathrm{H}_{2} \mathrm{O}+2 \mathrm{CaO} \cdot \mathrm{SiO}_{2} \rightarrow 2 \mathrm{CaO} \cdot \mathrm{SiO}_{2} \cdot \mathrm{CaSO}_{4} \cdot 6 \mathrm{H}_{2} \mathrm{O} \\
3 \mathrm{CaSO}_{4} \cdot 6 \mathrm{H}_{2} \mathrm{O}+3 \mathrm{CaO} \cdot \mathrm{Al}_{2} \mathrm{O}_{3}+25 \mathrm{H}_{2} \mathrm{O} \rightarrow 3 \mathrm{CaO} \cdot \mathrm{Al}_{2} \mathrm{O}_{3} \cdot 3 \mathrm{CaSO}_{4} \cdot 31 \mathrm{H}_{2} \mathrm{O}
\end{gathered}
$$

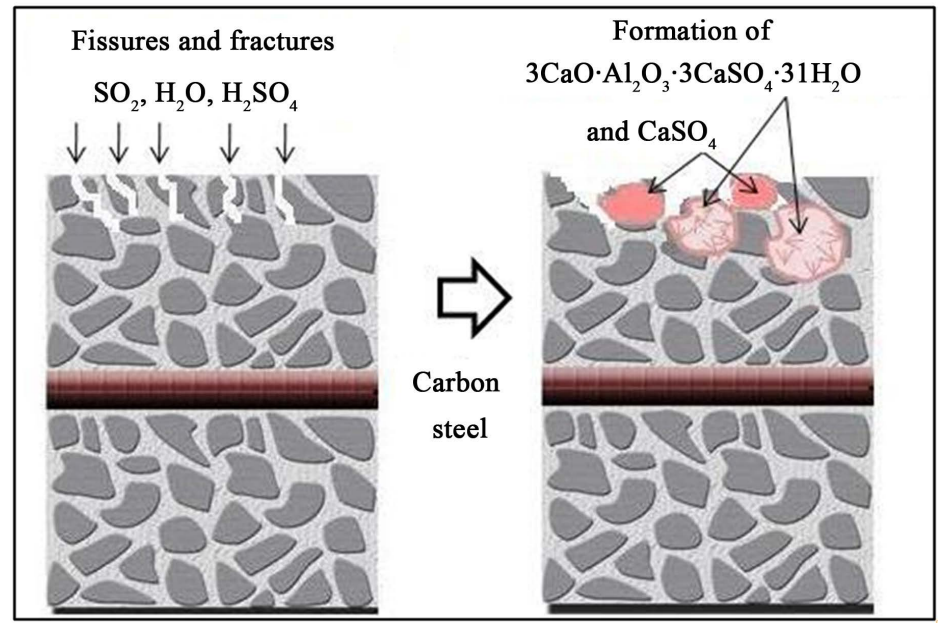

Figure 1. Chemical corrosion mechanism of concrete. 


\subsection{Electrochemical Corrosion of Reinforcing Steel or Rebar (Reinforcing Bar)}

Electrochemical corrosion is a spontaneous process, likely to occur when the metal or alloy is in contact with an electrolyte, which hosts both the anodic and cathodic reactions. The transfer of electrons from the anodic to cathodic regions is performed by a metallic conductor, and the diffusion of anions and cations in solution closes the electrical circuit.

The intensity of the etching process is evaluated by the number of ions discharged at the cathode, or the number of electrons that migrate from the anode to the cathode. The anodic and cathodic reactions involved; one aspect of this corrosion process is shown in Figure 2.

The electrolyte that migrates through the fissures of concrete and reaches the reinforcing carbon steel is essential for the occurrence of electrochemical corrosion and its aggressiveness is a function of the chemical constitution of the electrolyte and its $\mathrm{pH}$.

An acidic medium increases and promotes the intensity of electrochemical reactions. However, the corrosion of carbon steel can be minimized by contaminants, residues and oxides that adhere to the surface, forming a barrier and preventing or reducing the electrochemical reactions. The $\mathrm{Fe}^{2+}$ ions produced at the anodes combine with $\mathrm{OH}^{-}$ions from the cathodic reaction to ultimately produce a stable passive film of ferrous hydroxide $-\mathrm{Fe}(\mathrm{OH})_{2}$ - on the carbon steel surface by preventing or retarding the corrosion reaction:

$$
\mathrm{Fe}^{2+}+2 \mathrm{OH}^{-} \rightarrow \mathrm{Fe}(\mathrm{OH})_{2}
$$

An alkaline $\mathrm{pH}$, in the order of 9 to 12, favors the formation of these films.

Considering, then, that concrete is a porous material, it is this porosity that allows the ingress of corrosive species to the embedded reinforcing steel. In this case, the three most common cases are highlighted: generalized corrosion, localized corrosion and stress corrosion cracking (SCC), as shown in Figure 3.

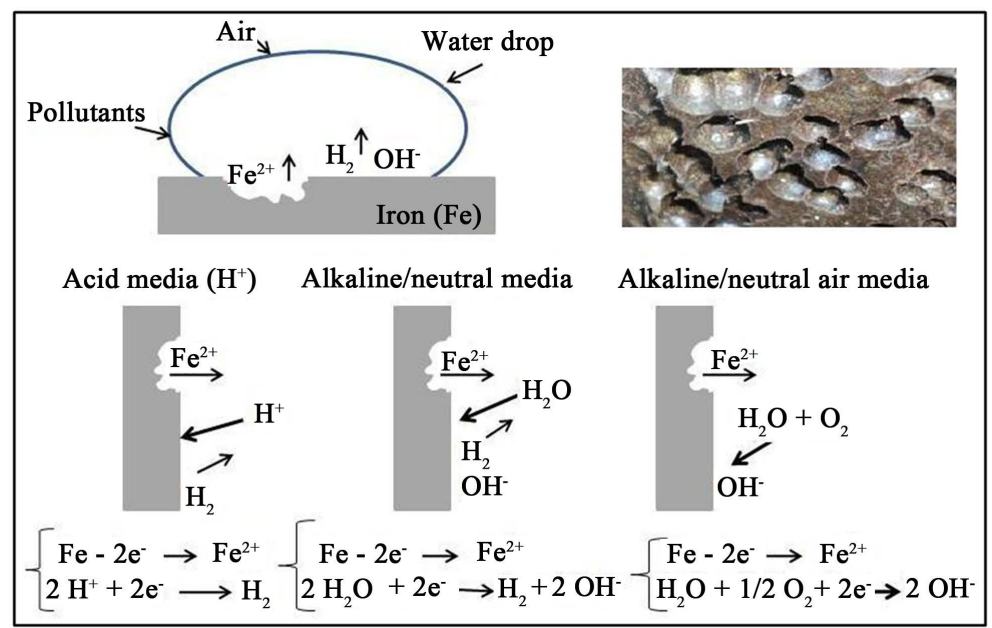

Figure 2. Mechanism of electrochemical corrosion.

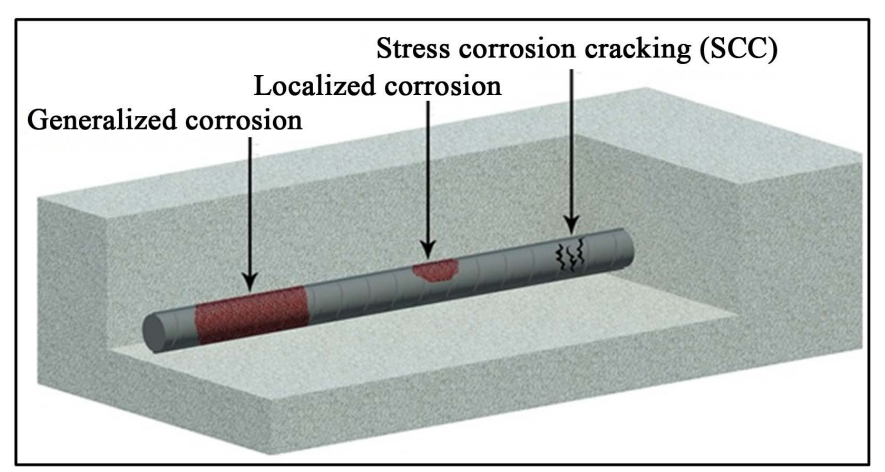

Figure 3. Examples of corrosion in reinforcing steel. 
Uniform corrosion is characterized by a corrosive attack proceeding evenly over the entire surface area or a large fraction of the total area. Rates of uniform attack are reported in various units, with accepted terminologies being millimeters penetration per year $(\mathrm{mm} / \mathrm{y})$.

Pitting corrosion is a localized form of corrosion by which cavities or holes are produced in the metal or alloy. In order for localized corrosion to occur, there must be a spatial variation in the electrochemical or metallurgical conditions. The occurrence of discrete sites of attack demonstrates that passivity must be able to coexist on the same surface with active regions. Pitting is considered to be more dangerous than uniform corrosion damage because it is more difficult to detect, predict, and design against.

Corrosion products often cover the pits [11]-[13]. However, disordered growth, porous and non-adherent can cause corrosion located under this deposit. The possible penetration of oxygen $\left(\mathrm{O}_{2}\right)$ along with water, mainly under the deposit of $\mathrm{Fe}(\mathrm{OH})_{2}$, favors the formation of ferric hydroxide $\mathrm{Fe}(\mathrm{OH})_{3}$ or hydrous ferric oxide (FeO·OH), according to the following reactions:

$$
\begin{gathered}
\mathrm{Fe}^{2+}+2 \mathrm{OH}^{-} \rightarrow \mathrm{Fe}(\mathrm{OH})_{2} \\
2 \mathrm{Fe}(\mathrm{OH})_{2}+1 / 2 \mathrm{O}_{2}+\mathrm{H}_{2} \mathrm{O} \rightarrow 2 \mathrm{Fe}(\mathrm{OH})_{3} \\
2 \mathrm{Fe}(\mathrm{OH})_{2}+1 / 2 \mathrm{O}_{2} \rightarrow 2 \mathrm{FeO} \cdot \mathrm{OH}+\mathrm{H}_{2} \mathrm{O}
\end{gathered}
$$

The consequent localized corrosion under the deposit is presented in Figure 4.

According to Revie and Uhlig [12], SCC is a type of cracking that occurs when a material that is susceptible to SCC is simultaneously stressed in tension and exposed to an environment that causes SCC.

Under environmental conditions and at an alkaline $\mathrm{pH}$, the possibility of this type of corrosion is practically nil. The possibility of this type of corrosion increases when with the formation of pits in the steel surface associated with the generation of atomic hydrogen $(\mathrm{H})$ in an acidic medium. The atomic hydrogen formed by the reduction of hydrogen ions $\left(\mathrm{H}^{+}\right.$) (in an acidic medium) migrates to the interior of the cavities (cracks and fissures) and penetrates microscopically in carbon steel to drive SCC, according to Figure 5. Molecular hydrogen $\left(\mathrm{H}_{2}\right)$, due to its large size compared to atomic hydrogen, does not migrate into the interior of the cavities. This problem usually occurs in welded joints and in high-strength steel and can also occur in steel subjected to high tension, as in pre-stressed concrete.

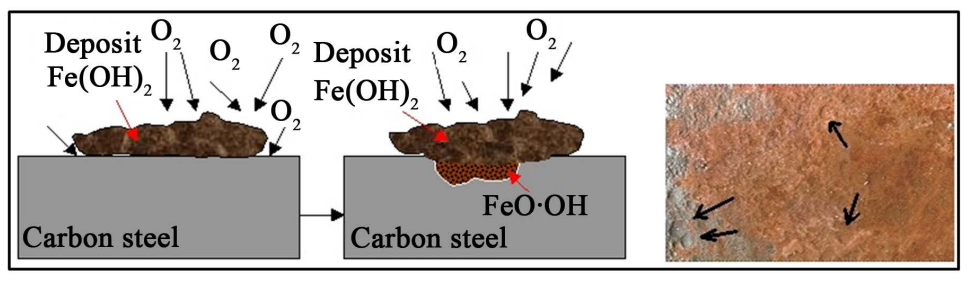

Figure 4. Localized corrosion under the deposit.

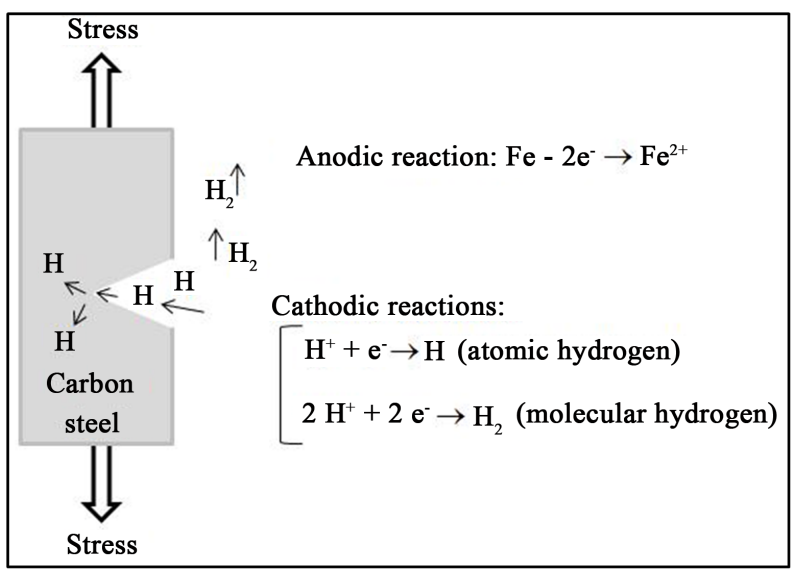

Figure 5. Mechanism of stress corrosion cracking. 


\subsection{Electrolytic Corrosion of Reinforcing Steel or Rebar (Reinforcing Bar)}

Electrolytic corrosion is characterized by an electrochemical process that occurs with external application of an electric current. This means that the process is not spontaneous corrosion. It is caused by leakage currents, also called stray currents, stray-current electrolysis, parasite currents, or strange currents. This phenomenon often occurs in oil pipelines, drinking water mains, telephone cables, buried tanks at gas stations, and reinforced concrete. Generally, these currents are due to deficiencies in insulation or grounding out of specifications [14] [15].

Typically, localized holes occur in isolated facilities where the stray current escapes from electric networks or electric railways into the ground, as shown in the proposed mechanism in Figure 6, while the image shown in Figure 7 illustrates major external wells and localized penetration of the walls of the tubes. It is observed that corrosion proceeds from the outside of the steel.

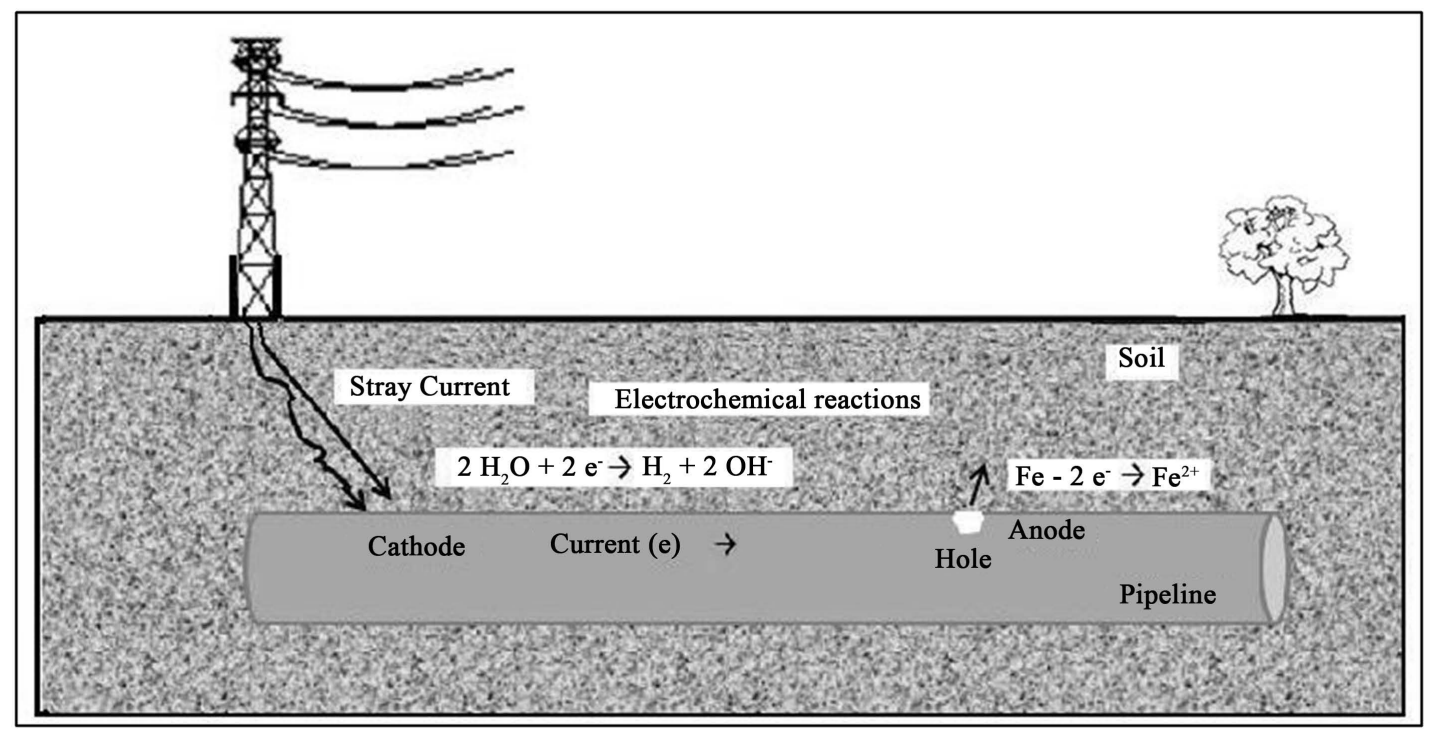

Figure 6. Mechanism of electrolytic corrosion.

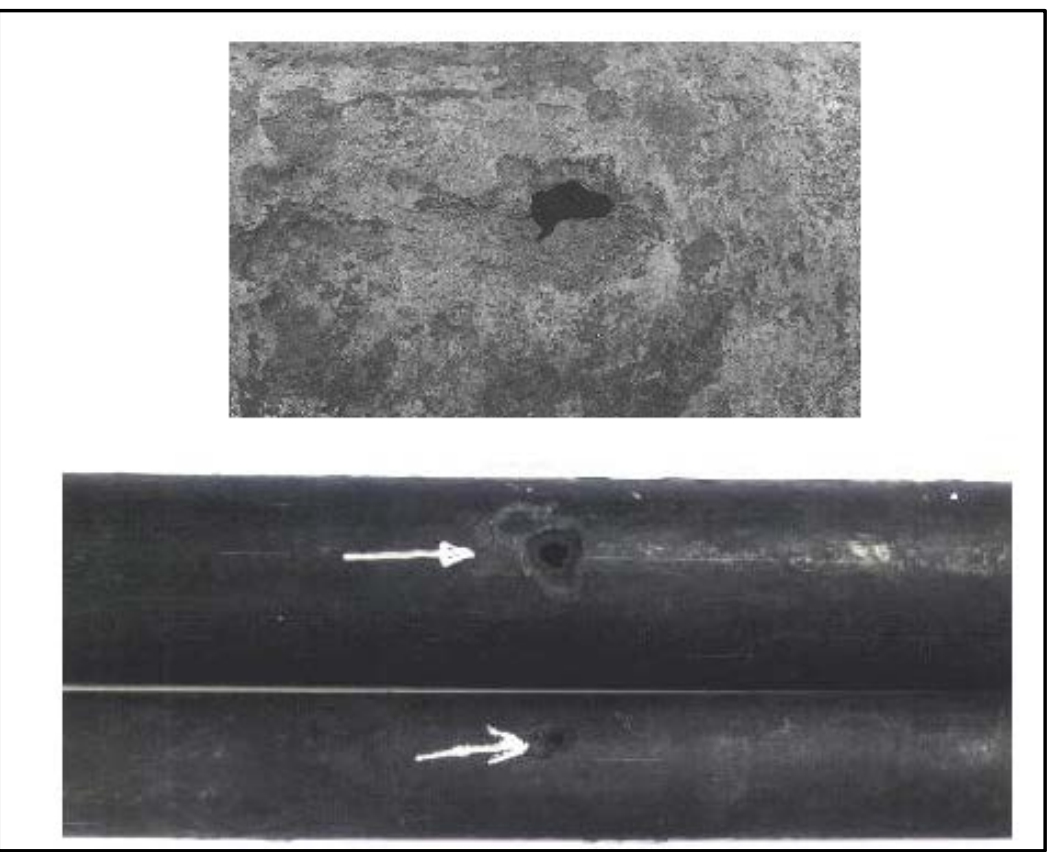

Figure 7. Examples of electrolytic corrosion. 


\section{Materials and Methods}

\subsection{Laboratory Tests}

To qualitatively evaluate the chemical attack of $\mathrm{SO}_{2}$ in environments with high humidity, four specimens of test cement were placed in an acrylic chamber (Figure 8), with the following dimensions: $50 \mathrm{~cm} \times 40 \mathrm{~cm} \times 40 \mathrm{~cm}$; the chamber was hermetically sealed and equipped with a continuous injection system of wet $\mathrm{SO}_{2}$ for 60 days. To represent special cement with no added calcium sulfate $\left(\mathrm{CaSO}_{4}\right)$, specimens were made in the form of $8 \mathrm{~cm}$ diameter discs with a mass mixture consisting of $60 \%$ calcium oxide $(\mathrm{CaO}), 20 \%$ hydrated sodium silicate $\left(\mathrm{Na}_{2} \mathrm{SiO}_{3} \times \mathrm{xH}_{2} \mathrm{O}\right), 10 \%$ aluminum oxide $\left(\mathrm{Al}_{2} \mathrm{O}_{3}\right)$ and $20 \%$ silicon oxide $\left(\mathrm{SiO}_{2}\right)$. The specimens were moist-cured for 5 days. All products used were of the highest purity.

After 60 days, the specimens were removed from the test and dried with hot air and samples were taken for $\mathrm{X}$-ray diffractometry analysis. On the first day of the test, the $\mathrm{pH}$ value measured on the surface of the specimens showed a variation from $\mathrm{pH} 4.5$ to 5.5. At the end of the test, the $\mathrm{pH}$ measured on the surface of the specimens was from 0.1 to 0.2 .

Excess $\mathrm{SO}_{2}$ that escaped through the vent was absorbed in a solution of sodium hydroxide $(\mathrm{NaOH})$.

\subsection{Evaluation of Reinforced Concrete Specimens Subjected to the Corrosive Action of $\mathrm{SO}_{2}$}

In Figure 9 are presented some of the analyzed samples of reinforced concrete subjected to contamination and deterioration caused by burning fuel oil with a high sulfur content.

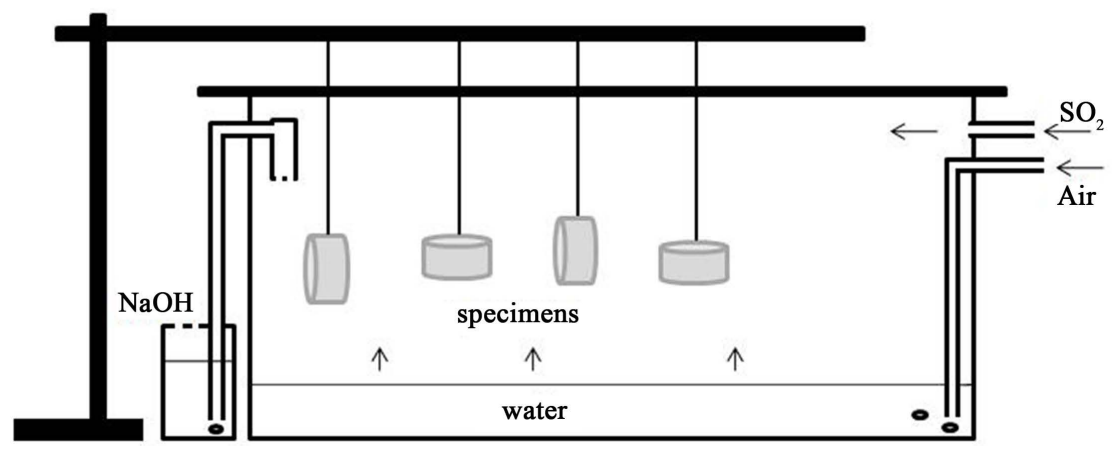

Figure 8. Assay of specimens of special cement in an $\mathrm{SO}_{2}$ and air mixture.

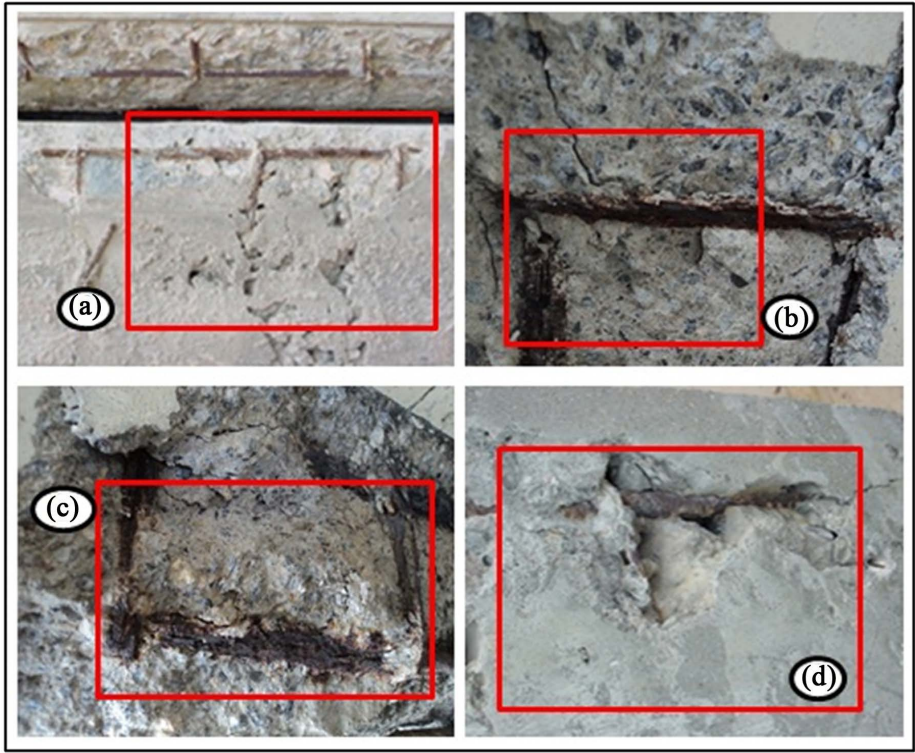

Figure 9. Example of corrosion in reinforcing steel. 
Three samples were taken from each identified area (A, B, C and D) marked on the concrete, aiming at the identification of calcium sulfate $\left(\mathrm{CaSO}_{4}\right)$ by X-ray diffractometry. In addition, three samples were taken for identification by the wet method for the presence of soluble sulfate $\left(\mathrm{SO}_{4}^{2-}\right)$.

For the evaluation of electrochemical corrosion in reinforced concrete, samples of carbon steel were taken from each area (A, B, C and D) indicated in Figure 7.

\section{Results and Discussion}

Analyses by X-ray diffractometry of samples removed on the surface of the specimens (laboratory test in an atmosphere of $\left.\mathrm{SO}_{2}\right)$ revealed the presence of calcium sulfate $\left(\mathrm{CaSO}_{4}\right)$, confirming that $\mathrm{SO}_{2}$ reacts with calcium oxide, leading to the deterioration of concrete as presented in Figure 1:

$$
\begin{gathered}
\mathrm{SO}_{2}(\mathrm{~g})+\mathrm{H}_{2} \mathrm{O}(\mathrm{aq}) \rightleftarrows \mathrm{H}_{2} \mathrm{SO}_{3}(\mathrm{aq}) \\
\mathrm{H}_{2} \mathrm{SO}_{3}+1 / 2 \mathrm{O}_{2} \rightarrow \mathrm{H}_{2} \mathrm{SO}_{4} \\
\mathrm{CaO}+\mathrm{H}_{2} \mathrm{SO}_{3}(\mathrm{aq}) \rightarrow \mathrm{CaSO}_{3}+\mathrm{H}_{2} \mathrm{O} \\
\mathrm{CaSO}_{3}+1 / 2 \mathrm{O}_{2} \rightarrow \mathrm{CaSO}_{4} \\
\mathrm{CaO}+\mathrm{H}_{2} \mathrm{SO}_{4} \rightarrow \mathrm{CaSO}_{4}+\mathrm{H}_{2} \mathrm{O}
\end{gathered}
$$

In the samples removed from the concrete referring to areas $\mathrm{A}, \mathrm{B}$ and $\mathrm{C}$ (Figure 7), the presence of calcium sulfate $\left(\mathrm{CaSO}_{4}\right)$ and calcium carbonate $\left(\mathrm{CaCO}_{3}\right)$ were identified qualitatively by X-ray diffraction. Only in sample C (Figure 7) was the presence of soluble sulfate $\left(\mathrm{SO}_{4}^{2-}\right)$ identified. These facts indicate that there was a chemical attack on concrete that can be understood as chemical corrosion.

In the carbon steel bar samples removed from the reinforced concrete structures (Figure 9) subjected to the corrosive action of burning fuel oil with high sulfur content, uniform corrosion (Figure 10) and localized corrosion (Figure 11) were observed.

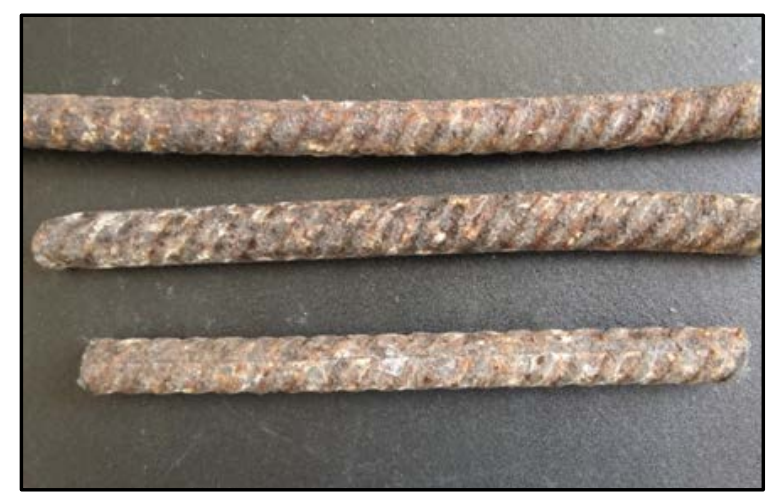

Figure 10. Carbon steel bars with uniform corrosion.

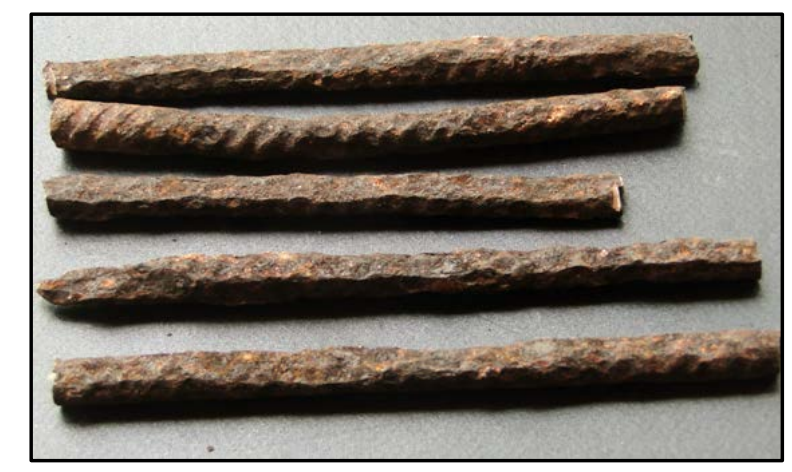

Figure 11. Carbon steel bars with localized corrosion. 
Figure 10 shows that the transverse diameter of the steel carbon bar remained constant. On the metallic surface, uniform passivation occurred along the carbon steel bar, preventing corrosion. These samples were removed from areas covered by concrete with a thickness greater than $40 \mathrm{~mm}$.

Figure 11 and Figure 12 show intense localized corrosion. These samples were removed from areas covered by concrete with a thickness of 20 to $30 \mathrm{~mm}$. The electrochemical reactions between water, oxygen, dioxide sulfur and the steel rebar led to corrosion initiation and long-term progression to severe damage in the concrete. The corrosive process resulted in a reduced cross-sectional area of the carbon steel rebar (from $10 \%$ to total disruption) and thus reduced the strength capacity of the material. Chemical analysis showed that the rust layer was formed of $\mathrm{FeO}, \mathrm{Fe}(\mathrm{OH})_{2}, \mathrm{Fe}_{3} \mathrm{O}_{4}$, and $\mathrm{FeO} \cdot \mathrm{OH}$. Thus, there was an increase in the volume of corrosion products. The expanded rust layer can cause concrete cracking and fragmentation, as shown in the diagram in Figure 13.

Suitable cover thickness, a high degree of compression, a lower water/cement ratio and increased curing time directly influence the permeability of concrete and the difficulty of penetration of aggressive agents. In construction, on the basis of these parameters, guidelines and procedures are generally recommended that depend on the aggressiveness of the corrosive medium; the cover thicknesses of concrete can vary from 25 to $55 \mathrm{~mm}$, as shown in Figure 14.

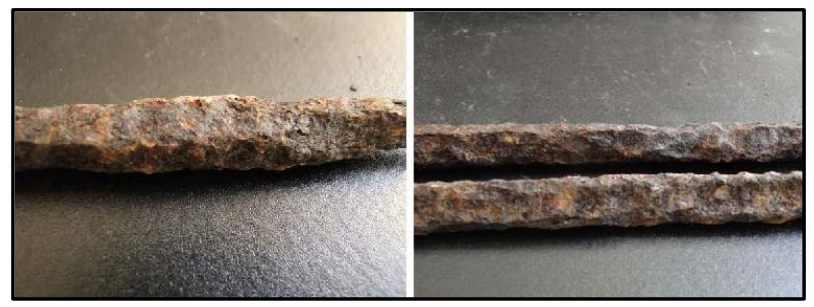

Figure 12. Carbon steel bars with localized corrosion.

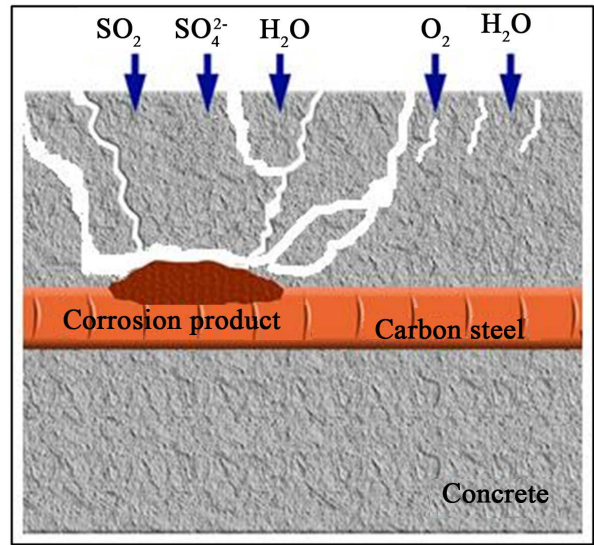

Figure 13. Fragmentation of reinforced concrete.

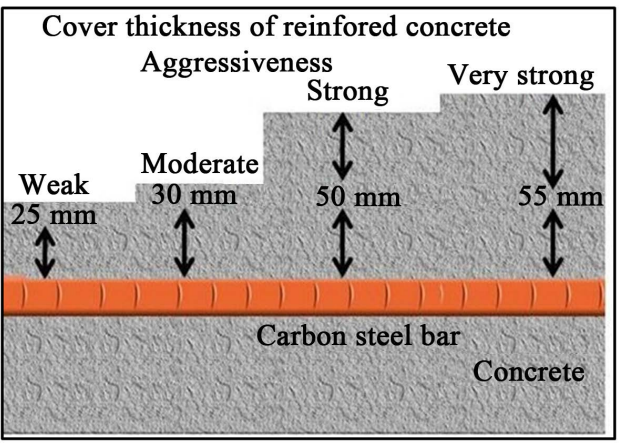

Figure 14. Cover thickness of reinforced concrete. 


\section{Conclusions}

Based on laboratory tests, chemical analyses, and inspections carried out at a site burning fuel with high sulfur content, it can be concluded that:

- The burning of fuel with high sulfur content favors the emission of $\mathrm{SO}_{2}$ and consequently the formation of sulfuric acid.

- The identification of $\mathrm{CaSO}_{4}$ in laboratory tests and in the concrete itself reveals and indicates the reaction of sulfuric acid with calcium silicates.

- Chemical corrosion of concrete is driven by the reactions and transformations of calcium silicates $\left(\mathrm{xCaO}^{-} \mathrm{SiO}_{2}\right)$ and calcium oxides $(\mathrm{CaO})$ as new products with a volume far superior to initial volumes of these constituents in the concrete, thus favoring the fragmentation of concrete.

- Electrochemical corrosion and deposit corrosion occur by electrolyte penetration $\left(\mathrm{SO}_{2}, \mathrm{O}_{2}\right.$ and water) to the carbon steel bar through faults, fissures and porosities that exist in reinforced concrete structure.

- The increase in the volume of the products of corrosion $\left(\mathrm{FeO}, \mathrm{Fe}(\mathrm{OH})_{2}, \mathrm{Fe}_{3} \mathrm{O}_{4}\right.$ and $\left.\mathrm{FeOOH}\right)$ of steel bars also causes the fragmentation of concrete.

- The corrosion of carbon steel bars occurs with greater intensity in areas covered by concrete with a thickness of less than $30 \mathrm{~mm}$.

- It is recommended that reinforced concrete structures in industrial areas (high aggressiveness) have a covering thickness of 50 to $55 \mathrm{~mm}$.

\section{References}

[1] Slunge, D., Ekbom, A. and Dahlberg, E. (2008) Serbia Environmental and Climate Impact Analysis. Environmental Economics Unit, Department of Economics, Göteborg University, School of Economics and Commercial Law.

[2] Moskalyk, R.R. and Alfantazib, A.M. (2003) Review of Copper Pyrometallurgical Practice: Today and Tomorrow. Minerals Engineering, 16, 893-919. http://dx.doi.org/10.1016/j.mineng.2003.08.002

[3] Tasić, V., Milošević, N., Kovačević, R. and Petrović, N. (2010) The Analysis of Air Pollution Caused by Particle Matter Emission from the Copper Smelter Complex Bor (Serbia). Chemical Industry \& Chemical Engineering Quarterly, 16, 219-228. http://dx.doi.org/10.2298/CICEQ090909011T

[4] Dimitrijevic, M., Kostov, A., Tasic, V. and Milosevic, N. (2009) Influence of Pyrometallurgical Copper Production on the Environment. Journal of Hazardous Materials, 164, 892-899. http://dx.doi.org/10.1016/j.jhazmat.2008.08.099

[5] Broder, J.M. (2010) E.P.A. Tightens Sulfur Dioxide Limits. The New York Times, 3 June 2010. http://www.nytimes.com/science/earth

[6] Smith, S.J., van Aardenn, J., Klimont, Z., Andres, R.J., Volke, A. and Arias, D. (2011) Anthropogenic Sulfur Dioxide Emissions, 1850-2005. Atmospheric Chemistry and Physics, 11, 1101-1116. http://dx.doi.org/10.5194/acp-11-1101-2011

[7] Baird, C. and Cann, M. (2005) Environmental Chemistry, Macmillan.

[8] Bravo, H.A., Soto, R.A., Sosa, R.E., Sanchez, P.A., Alarcón, A.L., Kahl, J. and Ruíz, J.B. (2006) Effect of Acid Rain on Building Material of the El Tajin Archaeological Zone in Veracruz, Mexico. Environmental Pollution, 144, 655660. http://dx.doi.org/10.1016/j.envpol.2005.12.052

[9] Wang, T.J., Jin, L.S., Li, Z.K. and Lam, K.S. (2000) A Modeling Studyon Acid Rain and Recommended Emission Control Strategies in China. Atmospheric Environment, 34, 4467-4477. http://dx.doi.org/10.1016/S1352-2310(00)00101-1

[10] Xie, S., Qi, L. and Zhou, D. (2004) Investigation of the Effects of Acid Rain on the Deterioration of Cement Concrete Using Accelerated Tests Established in Laboratory. Atmospheric Environment, 38, 4457-4466. http://dx.doi.org/10.1016/j.atmosenv.2004.05.017

[11] Roberge, P.R. (2000) Handbook of Corrosion Engineering. McGraw-Hill, New York.

[12] Revie, R.W. and Uhlig, H.H. (2008) Corrosion and Corrosion Control. An Introduction to Corrosion Science and Engineering. 4th Edition, John Wiley \& Sons, New Jersey.

[13] Kelly, R.G., Scully, J.R., Shoesmith, D.W. and Buchheit, R.G. (2003) Electrochemical Techniques in Corrosion Science and Engineering. Marcel Dekker, Inc., New York.

[14] von Baeckmann, W., Schwenk, W. and Prinz, W. (1997) Handbook of Cathodic Corrosion Protection. Theory and Practice of Electrochemical Protection Process. 3rd Edition, (GPF) Gulf Professional Publishing, Houston.

[15] Parker, M.E. and Peattie, E.G. (1997) Pipeline Corrosion and Cathodic Protection. 3rd Edition, (GPF) Gulf Professional Publishing, Houston. 